\title{
SOFTWARE: RECURSO TERAPEUUTICO OCUPACIONAL PARA ESTIMULAÇÃO COGNITIVA DO IDOSO
}

\author{
Angela Maria Bittencourt \\ Lidia Ferreira de Oliveira Machado² \\ Miriam Barrozo De Almeida ${ }^{3}$ \\ Daniel Ribeiro Pires ${ }^{4}$
}

resumo

Idosos com problemas cognitivos possuem declínio em sua capacidade funcional, tornando-se mais dependentes e com baixa qualidade de vida. O objetivo desse estudo é desenvolver um software baseado nos testes, nas atividades cotidianas descritas na literatura como as mais afetadas nesta população e da experiência do projeto de intervenção desenvolvido no Instituto Federal do Rio de Janeiro. Essa proposta se justifica por estudos comprovarem que, por meio da estimulação cognitiva, os idosos conseguem realizar melhor suas atividades rotineiras. Visa ao aprimoramento do funcionamento

1 Graduada em Terapia Ocupacional. Doutora em Ciências. Professora do Instituto Federal do Rio de Janeiro. E-mail: angela.silva@ifrj.edu.br.

2 Acadêmica de graduação de Terapia Ocupacional do Instituto Federal do Rio de Janeiro. E-mail: liliferreira_@hotmail.com.

3 Acadêmica de graduação de Terapia Ocupacional do Instituto Federal do Rio de Janeiro. E-mail: mairim-eu@hotmail.com.

4 Graduado em Ciência da Computação. Mestre em Computação. Professor do Instituto Federal do Rio de Janeiro. E-mail: daniel.pires@ifrj.edu.br. 
cognitivo, melhoria da qualidade de vida e da segurança nas realizações das atividades cotidianas buscando um desempenho mais competente, maior autonomia e independência. A metodologia utilizada foi de caráter exploratório, a partir do levantamento da literatura, que demonstrou que o questionário de Pfeffer, o Índice de Katz e a Medida Independência Funcional vinculada à funcionalidade das atividades da vida diária e as instrumentais que formam a base das áreas cognitivas mais afetadas. A partir desses dados, dividiu-se um software em dez exercícios, abrangendo as áreas específicas da cognição, pois o mesmo pode ser um recurso terapêutico ocupacional para idosos que necessitem de estímulo e intervenções em seu desempenho ocupacional. As informações foram dispostas em relação ao uso de cores e quantidade de elementos, pois estas facilitam ou dificultam o acesso e compreensão da interface. Concluiu-se que o software pode ser uma proposta positiva para diminuir gasto energético, porque as realizações dos exercícios favorecem a relação independência/dependência, aumentam a eficácia e as habilidades requeridas para praticá-los.

palavras - chave

Envelhecimento. Estimulação cognitiva. Software. Terapia ocupacional.

O envelhecimento pode ser entendido como processo dinâmico e progressivo caracterizado tanto por alterações morfológicas, funcionais e bioquímicas, quanto por modificações psicológicas. Essas modificações determinam a progressiva perda da capacidade de adaptação ao meio ambiente, ocasionando maior vulnerabilidade e maior incidência de processos patológicos, que podem levar o indivíduo à morte (PAPALÉO NETTO; CARVALHO FILHO, 2006).

Como uma de suas consequências, o envelhecimento pode trazer a diminuição gradual da capacidade funcional, associadas à dependência, que acarreta restrição/perda de habilidades ou dificuldades de executar funções e atividades relacionadas à vida diária. Tais dificuldades são ocasionadas pelas limitações físicas e cognitivas, que muitas das vezes devem-se à diminuição do volume cerebral e da velocidade de processamento.

A capacidade funcional pode ser definida como a manutenção da capacidade de realizar Atividades Básicas da Vida Diária (ABVD) e Atividades 
Instrumentais da Vida Diária (AIVD), necessárias e suficientes para uma vida independente e autônoma. Para o idoso, a realização das ABVD aparece como algo presente e necessário para a sua sobrevivência, mantendo-o participativo na gestão e nos cuidados com a própria saúde, e no desenvolvimento de tarefas domésticas (OLIVEIRA; MENEZES, 2011).

Na busca de uma melhor qualidade de vida, fruto de um envelhecimento com independência e autonomia, saudável e ativo, tem-se desenvolvido diferentes técnicas de reabilitação, que levam em consideração a teoria da plasticidade cerebral, que é a capacidade de reorganizar as redes neurais, modificando o recrutamento neuronal, ocorrendo de acordo com a idade da pessoa e do nível de demanda da tarefa, sugerindo uma reorganização funcional e ativações compensatórias em busca de manter a capacidade cognitiva (PASCHOAL, 2007; PORTO; NITRINI, 2014; SANTOS et al., 2012; CAIXETA; PINTO, 2014). A terapia ocupacional, ao pensar na população idosa, visa manter e prevenir o desempenho ocupacional dos indivíduos, procurando adaptar a capacidade remanescente e adequando o grau de dificuldade da tarefa ou da atividade (TAMAI, 2003).

As Atividades de Vida Diária (AVD's) incluem tarefas básicas, como banhar-se, vestir-se, locomover-se, ter continência de esfíncteres, alimentar-se, mobilidade funcional, autocuidado, atividade sexual, entre outras. E como Atividades Instrumentais de Vida Diária (AIVD), aquelas que se destinam a apoiar as tarefas dentro de casa como cozinhar, arrumar a casa, telefonar, lavar roupa, ir às compras, cuidar das próprias finanças e tomar remédios e na comunidade como: cuidar dos outros, cuidar de animais, educar crianças, gerenciar comunicação (transmitir recados), prática religiosa, manter sua segurança e dos outros, entre outras atividades (STHAL; BERTI; PALHARES, 2011).

Além dessas duas áreas de ocupações, encontram-se a participação social, descanso e sono, brincar, educação, trabalho e o lazer. Enquanto executa suas atividades, o idoso utiliza suas habilidades percepto-sensoriais vinculadas à noção de tempo e espaço (localizar no ambiente intra e extrafamiliar): responder às sensações, realizando associações, interpretando, organizando os vários estímulos ligados à audição, à visão, ao tato, a propriocepção, ao paladar, ao olfato, e ao sistema vestibular; cognitivas demonstradas por meio de comportamentos ou ações usadas ao planejar o desempenho de uma atividade; regulação emocional presente em comportamentos ou ações utilizadas para identificar, gerenciar e expressar sentimentos durante a interação com outros ou em suas atividades (ex. apesar das dificuldades encontradas em suas atividades, tenta solucioná-las sem se desinteressar pelo que está realizando). 
As atividades práxicas exigem movimentos propositados, sequenciais de organização no tempo e espaço, precisando da cognição para assimilar o conteúdo da mensagem. Essas ações conscientes constituem-se no ato motor que interage fisicamente com as tarefas, o contexto, o ambiente e os objetos; de cunho social ou de comunicação que se encontram nos comportamentos do ser humano, favorecendo à comunicação e a interação com outros (CARLETO et al., 2010).

Dessa forma, algumas funções cognitivas começam a declinar com a idade, tais como as funções executivas, funções atentivas, memória de trabalho, habilidades viso-espaciais, acarretando ao idoso maior dificuldade em interagir com o mundo a sua volta (DRAG; BIELIAUSKAS, 2010). Assim, as funções executivas, predominantemente relacionadas ao lobo frontal, são responsáveis pelo planejamento e organização do pensamento, inibição de estímulos distratores, auto monitoramento e controle inibitório. Enquanto as funções atentivas se caracterizam pela capacidade de manipular e redirecionar os recursos de atenção de acordo com o estímulo: ao realizar tarefas concomitantes (atenção dividida), manter a atenção (atenção sustentada), habilidade de mudar de um estímulo para o outro (atenção alternada) ou a capacidade de selecionar estímulos relevantes (atenção seletiva). Indivíduos com transtornos cognitivos apresentam empecilhos e dificuldades para realizar algumas atividades, as quais podem advir tanto de estruturas do corpo comprometidas (partes anatômicas, órgãos, membros e seus componentes), de funções do corpo (sistemas orgânicos incluindo as funções psicológicas ou habilidades), da cognição, bem como as do ambiente e que seus estímulos favorecem ou não o desempenho de tarefas (PASCHOAL, 2007).

A atenção pode ser definida como um fenômeno por meio do qual pode ser processada ativamente uma quantidade de informações disponíveis nos órgãos dos sentidos, das memórias armazenadas e de outros processos cognitivos (STERNBERG, 2000). Seu mecanismo é fator importante no viver diário do ser humano, pelos frequentes estímulos sensoriais provenientes do exterior e do interior do organismo que se transformam em informações que ultrapassam a capacidade de processamento do sistema nervoso (MACHADO; HAERTEL, 2015).

A atenção é assim um processo complexo que necessita da divisão em múltiplas operações, sendo fator fundamental da atividade sensorial, da memória e participa como distribuidor da atividade sensorial pelos vários níveis da consciência que processam a informação (CASTRO-CALDAS, 2005). Quando alterada ela afeta todas as funções cognitivas, fazendo com que as informações fiquem soltas e confusas. 
A memória é uma função psíquica bastante complexa e dividida em setores (CORRÊA, 2010, p. 570). Para Baddeley, Eysenck e Anderson (2011) ela pode ser dividida em memória de curta duração e de trabalho, cuja finalidade é a retenção temporária de pequenas quantidades de informação sobre breves períodos de tempo e sua importância se dá no sentido de garantir a lembrança imediata e temporária; memória semântica, cuja finalidade é armazenar conhecimento sobre o mundo.

Segundo Lent (2004), quanto ao tempo de duração, a memória pode se dividir em: a) ultrarrápida: a retenção dura de frações de segundo a alguns segundos, memória sensorial. Por exemplo, ouvir alguém ditando um número de telefone, na hora você lembra, mas quando passa uns segundos é incapaz de recordar; b) de curta duração ou de trabalho: seu acesso rápido e limitado dura minutos ou horas e garante o sentido de continuidade do presente. Nessa memória, inclui-se a memória operacional que servirá para organizar a realidade percebida pelo cérebro, pois ela armazena informações essenciais para a resolução de problemas, para o uso de raciocínio rápido ou elaboração de comportamentos (que podem ser esquecidos a seguir): um exemplo dela é lembrar o local onde se estacionou o carro; c) de longa duração (ou permanente): dura horas ou anos e garante o registro do passado autobiográfico e dos conhecimentos do indivíduo. Dessa forma, ela é responsável por armazenar todo o conhecimento de uma pessoa.

Existem duas fontes de informação que entram na memória a curto-prazo, uma proveniente da memória sensorial e outra da memória de longo-prazo. Esta última acontece na fase de recuperação da memória, uma vez que as informações armazenadas na memória de longo-prazo são transferidas de volta à memória de curto-prazo para poder ser interpretada (GRIEVE; GNANASEKARAN, 2010).

Para esses estudiosos, a memória pode variar de acordo com sua natureza, sendo classificada em: a) Memória declarativa (ou explícita): expressa e/ ou descrita por meio de palavras, faz parte da memória permanente - fatos, nomes, acontecimentos; b) Memória episódica: tem referência temporal, memória de fatos sequenciais (eventos com data); c) Memória semântica: envolve conceitos atemporais, memória cultural; d) Memória não declarativa (ou implícita): não pode ser expressa/descrita por meio de palavras, é aprendida de modo mecânico (ex. aprender a dirigir); e) Memória de representação perceptual: representa imagens sem significado, é conhecida como pré-consciente; f) Memória de procedimentos: representa as habilidades e hábitos (ex. andar de bicicleta); g) Memória associativa: associa dois ou mais estímulos (condicionamento clássico) ou um estímulo a certa resposta (condicionamento operante), caracteriza-se, 
por exemplo, ao olhar para um alimento saboroso, começa-se a salivar, pois a imagem encontra-se associada à lembrança do cheiro, do sabor ou ao aspecto do alimento; h) Memória não associativa: atenua uma resposta (habituação) ou a aumenta (sensibilização) por meio da repetição de um mesmo estímulo se aprende sem perceber (ex. latido de um cão não traz riscos) e; i) Memória operacional: a qual permite o raciocínio e o planejamento do comportamento.

Sendo assim, o idoso necessita da atenção para gerar memória de longo prazo e armazenar suas informações, pois ao receber uma nova informação ela é comparada com o que já se tem armazenado e a sua integração é realizada por comparações, respostas e adaptações. Esse processo é denominado de processamento cognitivo, no qual a percepção tem relação com a experiência de mundo (GRIVE; GNANASEKARAN, 2010). Logo, o declínio cognitivo é fator comprometedor da capacidade funcional do idoso, afetando inicialmente as AIVD's, antes das AVDs, consequentemente a última será afetada, nos estágios demenciais mais avançados (TALMELLI et al., 2010; LOUREIRO, 2011).

Existem alguns testes utilizados em pesquisas para avaliar o grau de funcionalidade do idoso, nos quais identifica-se o grau de independência e dependência nas atividades cotidianas. Para a avaliação funcional foram usada as escalas IQCODE, DAFS-R, DAD, ADL-Q; para avaliação das atividades instrumentais da vida diária, a escala Bayer e; para a avaliação das atividades básicas, a escala Katz. Como instrumento de rastreio, deve-se utilizar o Mini Exame do Estado Mental; quanto às baterias multifuncionais, pode-se aplicar CAMCOG-R, ADAS-COG, CERAD e MDRS, que avaliam brevemente várias funções cognitivas, disponíveis para uso na nossa língua (CHAVES et al., 2011).

A escala de Pfeffer avalia as atividades instrumentais de vida diária, com 10 questões que variam de zero (0) a três (3) pontos, na qual 0 significa que realiza normalmente ou nunca fez e poderia fazê-lo e 3 não é capaz, podendo atingir até 30 pontos. A pontuação acima de cinco (5) pontos já caracteriza o idoso como dependente (PFEFFER et al., 1982).

A escala Katz avalia as Atividades Básicas da Vida Diária (ABVD), a qual foi adaptada transculturalmente para uso com população brasileira e foi mais frequentemente utilizada em estudos com pacientes com demência (LINO et al., 2008). Ela avalia as tarefas de banhar-se, vestir-se, locomover-se, alimentar-se, ser continente, usar sanitário. A prova é baseada no exercício de cada atividade e não na afirmação da capacidade de realizar (SANTOS; PAVARINI, 2011). A pontuação é: A (independente em todas as funções), B (independente em cinco funções); $\mathrm{C}$ (independente em todas exceto lavar-se e outra); D (independente em todas exceto lavar-se, vestir-se e outra); E (independente em todas exceto, lavar-se, vestir-se, usar sanitário e outra); F 
(independente em todas exceto lavar-se, vestir-se, usar a sanita, mobilizar-se e outra) e $G$ (dependente em todas as funções).

A MIF possui 18 itens: alimentação, higiene pessoal, banho, vestir-se abaixo da cintura, vestir-se acima da cintura, uso do vaso sanitário, controle de urina e fezes, transferência para cama/cadeira de rodas, transferência para o vaso sanitário e transferência para o chuveiro, marcha/cadeira de rodas e escadas completam a MIF motora que se soma à parte de avaliação cognitiva constituída de interação social, resolução de problemas e memória. O score da escala vai de 18 a 126 e cada item recebe de 1 a 7 pontos, na qual 1 significa dependência total e 7 independência completa (TALMELLI et al., 2013).

A reabilitação cognitiva se baseia na execução de atividades para manter ativa a atenção, concentração, sequência de pensamento e capacidade de fazer escolhas (DIAS, 2014). Ela se desenvolve em três etapas: a) Restauração: a qual atua diretamente sobre as funções cognitivas alteradas; b) Compensação: desenvolvimento de capacidade para compensar a função alterada e c) Substituição: novo meio de realizar a tarefa de maneira a minimizar o efeito da disfunção cognitiva. A estimulação cognitiva visa gerar melhora e manutenção do funcionamento cognitivo (RODA, 2013), assim sendo, o software desenvolvido por meio deste estudo que proporcionará o estímulo à cognição, torna-se aliado do terapeuta ocupacional ao realizar o cuidado na reabilitação cognitiva.

Silva et al. (2013) coloca que o uso do computador como recurso terapêutico ${ }^{5}$ é crescente, o que favorece a inclusão digital de idosos, além de ser fator de estímulo à cognição e o aproxima de pessoas, o que diminuiria a sensação de solidão e isolamento da população acima de 60 anos. Esse recurso proporciona a aquisição e ampliação da autonomia e da independência, podendo evitar deslocamentos que necessitem de supervisão, como compras presenciais ou pagar contas pela internet.

No atendimento de terapia ocupacional, o computador pode se adequar ao idoso, ou cliente com déficit físico ou cognitivo, com hardwares ou softwares, de acordo com os objetivos terapêuticos, incluindo a vantagem de diminuir os gastos energéticos, pois pacientes com doenças crônicas, por exemplo, problemas cardíacos, devem reduzir os esforços (WATANABE; TSUKIMOTO, D.; TSUKIMOTO, G., 2003). Além de possibilitar a socialização que este pode proporcionar por meio da internet e redes sociais.

\footnotetext{
5 Recursos terapêuticos podem ser atividades, objetos, técnicas e métodos utilizados com o objetivo de auxiliar o cliente durante seu processo de reabilitação. Os recursos terapêuticos podem facilitar a realização de atividades, de forma a promover a independência pessoal e a melhora da funcionalidade e qualidade de vida.
} 
Para desenvolver um software que se adequasse a essa população, seria necessário compreender as questões clínicas pertinentes ao envelhecimento e suas patologias cognitivas levando em consideração os domínios mais acometidos. Nesse sentido, o mesmo foi sendo construído com as idosas do projeto de pesquisa Viver a vida, a Atuação da Terapia Ocupacional na Gerontologia. Por exemplo, ao ser detectado a dificuldade de sequenciar uma tarefa, ela foi projetada no software com um jogo de sequência sonora.

Outro item importante na criação do software é a forma como a informação será expressa e disposta em relação ao uso de cores e quantidade de elementos (PEDROSA; TOUTAIN, 2005), pois estas facilitam ou dificultam o acesso e a compreensão da interface. Sendo assim, a cor facilita a interação usuário-sistema à medida que se adequa às suas prioridades. Levando em consideração que o envelhecimento acomete a acuidade visual, o contraste se faz necessário para melhor compreensão.

A proposta de se utilizar o software junto ao terapeuta é para que este, ao ver dificuldades na realização das etapas, trabalhe além do uso do mesmo, outros recursos e estratégias, enriquecendo o repertório de possibilidades, treinando a atividade, adequando-a às necessidades desse cliente, possibilitando que o mesmo continue engajado e ativo. $\mathrm{O}$ treino das AVD em suas duas categorias, as atividades básicas ABVD's e as instrumentais AIVD's fazem parte da competência do terapeuta ocupacional de acordo com o artigo $1^{\circ}$ da Resolução 316 , de 19 de julho de 2006 (COFFITO, 2006).

Desta forma, o objetivo desse estudo foi desenvolver um software para intervenção específica para cada déficit cognitivo do idoso na busca de gerar benefícios da intervenção no seu dia-a-dia, uma vez que se encontram representadas, maioritariamente, nas situações do quotidiano nos exercícios de treino.

\section{Metodologia}

O presente software foi desenvolvido juntamente com o Laboratório de Aplicações Computacionais (LAC), do Instituto Federal do Rio de Janeiro (IFRJ), campus Nilópolis, o qual foi responsável pelo desenvolvimento da arte, interface e funções do jogo. Este laboratório conta com diversos membros das áreas de Matemática e Computação, incluindo alunos bolsistas de Iniciação Científica.

A coleta de dados ocorreu no desenvolver da pesquisa com as idosas do projeto, no decorrer de três anos. Para tal, utilizou-se o questionário de

6 Dispõe sobre a prática de Atividades de Vida Diária, de Atividades Instrumentais da Vida Diária e Tecnologia Assistiva pelo Terapeuta Ocupacional e dá outras providências. 
Pfeffer et al. (1982), Índice de Katz, Medida Independência Funcional (MIF) e da experiência desenvolvida como acadêmica bolsista no Instituto Federal, no qual oportunizou a experiência de três anos junto a idosos ativos da zona oeste do Rio de Janeiro, os quais forneceram dados das áreas cognitivas mais comprometidas no envelhecimento ativo e, a partir desse levantamento, optou-se pela construção dos jogos.

A primeira etapa constou de uma revisão literária de artigos e livros em português, no período de 2005 a 2015, nas bases de dados Scielo e Lilacs, tendo como descritores a cognição, saúde do idoso e terapia ocupacional. Teve-se como critério de inclusão as atividades citadas na literatura como mais comumente afetadas no idoso, vivenciadas na pesquisa e presentes em testes dentro da atuação do terapeuta ocupacional. E critério de exclusão as atividades que tinham mais de quatro etapas, tornando-se complexas para o público alvo.

O software foi composto por dez exercícios que envolveram habilidades cognitivas e percepto-sensoriais relacionadas a situações cotidianas, os quais passaram por atualizações, pois os exercícios tornam-se rotineiros e passam a serem automatizados, não prejudicando a eficácia da ferramenta. O software foi projetado em Hypertext Markup Langua (HTML 57), para se obter cores contrastantes, utilizou-se o kuler $^{8}$, a interação com a tela é feita pelo mouse por meio do click, ou clicar e arrastar, sendo possível acessá-lo via internet.

Foram levadas em consideração para nortear a construção do software as diferentes funções mentais que englobam a consciência, a orientação, o temperamento e a personalidade, a energia e direção, o sono (processo fisiológico), a atenção, a memória, a percepção, o pensamento, a função mental de sequenciamento do movimento complexo, a experiência do eu e de tempo (CARLETO et al., 2010).

\section{Resultados}

O software foi gerado pelo resultado da pesquisa com as idosas e pela revisão da literatura, composto por dez jogos que visam estimular cognitivamente o idoso. Exige habilidades para realização de tarefas, cujo contexto é virtual.

\footnotetext{
7 Linguagem para estruturação e apresentação de conteúdo para a World Wide Web e é uma tecnologia chave da Internet originalmente proposto por Opera Software ele adiciona várias novas funções sintáticas. Elas incluem as tags de<video>,<audio>,<header> e elementos<canvas>, assim como a integração de conteúdos Scalable Vector Graphics (SVG). Estas funções são projetadas para tornar mais fácil a inclusão e a manipulação de conteúdo gráfico e multimídia na web.

8 Aplicativo baseado na Web usado para experimentar, criar e compartilhar temas de cores a serem usadas no projeto.
} 
Assim, as habilidades práxicas são requeridas para a interação com a tela por meio das habilidades viso-motoras, por meio do clique ou clique e arraste.

Dentro das habilidades percepto-sensorial, a primeira meta foi o estímulo à interpretação, associação, organização discriminando sensorialmente, respondendo às sensações segundo à visão, audição e propriocepção. A segunda se vincula à regulação emocional, que une a persistência e a frustração. E a terceira abrange a esfera cognitiva como o sequenciar, organizar e planejar a tarefa, que fazem parte das funções executivas como categorizar, memorizar, nomear, entre outros.

O estudo de Santos e Pavarini (2011) refere que o índice de Katz (atividades básicas de vida diária) detectou que as maiores dificuldades encontradas abrangem o vestir-se, a higiene pessoal, o banho, a resolução de problemas, a memória, além de controle de urina e o uso do vaso sanitário. O que vêm reforçar Talmelli et al. (2010) sobre a Medida de Independência Funcional (MIF) que encontrou essas mesmas dificuldades.

Os jogos trabalham diretamente as áreas de ocupação: $A B V D$ vestir-se (escolha do tipo de roupa); $A I V D$ preparo de refeição (selecionar o que deseja comer, verificar o que se tem para preparar, descascar, cortar, cozinhar, temperar, servir, comer e arrumar a cozinha); estabelecimento e gerenciamento do lar (cômodos e objetos, lavar roupa); lazer (uso de cartas de baralho) e; exercícios de orientação temporal, percepção em profundidade e sequenciamento, memória, atenção, categorização, pensamento abstrato e funções executivas. Ao iniciar o jogo, existem quatro avatares ${ }^{9}$ (homem/mulher) para que os jogadores escolham com qual deles desejam jogar. Os avatares possuem características de acordo com a idade do público alvo, vinculando características pessoais do idoso. Foram criadas as seguintes características: cor e tamanho do cabelo, óculos, chapéu e os objetos utilizados no software são de uso cotidiano, assim sendo de fácil identificação.

O primeiro exercício se relaciona com a ABVD e consiste em vestir o boneco de acordo com o comando dado na tela. São cinco peças soltas e o idoso deverá selecionar o tipo adequado de roupa, incluindo o clima ou o estilo de roupa indicada. O objetivo é que se clique e arraste a(s) peça(s) para vestir o boneco obedecendo ao comando dado e à sequência lógica. Objetiva-se o reconhecimento das categorias de roupas, orientação tempo-espacial, ou seja, percepção de calor e frio.

9 Em informática, avatar é um ciber corpo inteiramente digital, uma figura gráfica de complexidade variada que empresta sua vida simulada para o transporte identificatório de "cibernautas" para dentro dos mundos paralelos do ciber espaço. 
O segundo exercício possui uma lista contendo quatro ingredientes de uma receita e a tela final pergunta: "Qual ingrediente esquecido?". Objetiva-se estimular a atenção, a concentração e a memória episódica e de trabalho (ex. fazer bolo).

O terceiro exercício inicia com um utensílio na tela e outras figuras na parte inferior, onde se encontram mais cinco figuras, deve-se encontrar a figura associável, estimulando a percepção, memória semântica e a associação.

O quarto exercício inicia-se com uma frase na tela que conta uma história em relação a determinado evento (ex. 2+4=) ou data, o idoso deve selecionar a opção da resposta por meio de duas setas, uma para cima e outra para baixo, na parte inferior do botão de resposta. Visa aprimorar a orientação temporal, cálculo e o raciocínio lógico.

No quinto exercício surge um relógio com números arábicos, aparece determinada hora, sendo preciso posicionar os ponteiros. Explora-se a memória semântica e a orientação temporal.

O sexto exercício consiste em quatro lâmpadas nas cores primárias que acendem e reproduzem cores e sons diferentes em sequência. $O$ objetivo é que o usuário seja capaz de sequenciar as cores e os sons. A cada sequência certa é adicionada mais uma cor. Explora-se a atenção, a memória de trabalho, o sequenciamento, a percepção visual e a habilidade viso-motora.

O sétimo exercício consiste em separar objetos (ex. lençol, panela, sabonete etc.) em devidos cômodos (ex. quarto, banheiro, sala, cozinha). Na tela aparecem fotos dos objetos e dos cômodos, o participante tem que associar o objeto ao cômodo. Abrangendo as categorias cognitivas de associação, memória semântica e percepção.

No oitavo exercício deve-se ler e procurar pela sombra do objeto ou palavra em meio a outras cinco sombras. Para isso, é preciso clicar em cima da sombra que corresponde ao objeto ou palavra. Essa tarefa necessita de pensamento abstrato, figura-fundo (habilidade visual que permite detectar, diferenciar e selecionar estímulos visuais dentro de um entorno determinado), atenção seletiva, controle inibitório e memória semântica.

O nono exercício possui roupas espalhadas de diversas cores na parte inferior da tela, uma máquina de lavar e o sabão em pó. O idoso deve separar as roupas pelas cores (discriminação de cores) e realizar o sequenciamento do lavar roupa (separar, colocar na máquina, ligar e tirar a roupa da máquina), correspondente à memória de trabalho.

Por fim, o décimo exercício apresenta comando de busca. Surge um jogo de cartas e o idoso tem que completar a sequência, levando em consideração a 
cor, o naipe, o número e a letra. Esse exercício envolve as funções executivas, a atenção à discriminação e a percepção de forma (igual/diferente).

\section{Discussão}

O avanço científico e tecnológico ocorrido nas últimas décadas transformou profundamente o modo de vida da população mundial e vem afetando o grupo de pessoas com mais de 60 anos, os quais buscam inserir-se na era digital. Nesse sentido, o presente estudo realizou a construção de um software para auxiliar na estimulação de tarefas de vida diária para idosos.

Segundo Freire e Sommerhalder (2000), essa "sociedade da informação", veio com o processo da globalização, no qual a internet aproximou as conexões entre os diferentes contextos sociais com grande qualidade da veiculação da informação. A utilização das ferramentas digitais, como os computadores, potencializou a melhoria da qualidade de vida das pessoas na medida em que encurtou distâncias e favoreceu a aproximação, disponibilizando serviços sem a necessidade de sair de casa, além de estimular o processamento cognitivo.

Nesse sentido, estudos como o de Talmelli et al. (2010) vêm mostrar que idosos com déficits cognitivos possuem dependência maior, trazendo prejuízo no funcionamento físico, social e emocional, estando a independência atrelada ao desempenho cognitivo, mas que, ao se inserirem recursos positivos disponíveis no meio ambiente como o bom estado psicológico do idoso, o uso da internet, acarreta o uso de estratégias de enfrentamento mais adequadas e eficazes na vida do idoso (BECKERT; IRIGARAY; TRENTINI; 2012, SANTOS; PAVARINI, 2011).

Outro teste utilizado ao longo dos estudos para caracterizar/relacionar prejuízos nas atividades cotidianas dos idosos foi o questionário de Pfeffer (atividades instrumentais da vida diária), correlacionando-o à dependência ou à independência desses em controlar finanças pessoais, cozinhar, entre outros fatores vinculados a sua rotina diária (SANTOS; PAVARINI, 2011, LOUREIRO, 2011, LIRA; RUGENE; MELO, 2011). Para trabalhar a AVD (ABVD e AIVD), foi registrado no questionário de Pfeffer e da MIF como uma das áreas potencialmente afetadas, em quadros demenciais graves ao se optar pela tarefa específica, apenas a seleção do tipo de roupa por ser uma habilidade cognitiva, o julgamento de roupas adequadas a situações (CARLETO et al., 2010).

$\mathrm{Na}$ AIVD, o preparo de alimentos requer atenção aos ingredientes dados e a sua memorização. Nesse sentido, favorece a memória e a atenção, devendo memorizar e recordar os ingredientes e identificar qual ingrediente está 
faltando, por meio da utilização de sua memória semântica; o reconhecimento dos utensílios de cozinha e sua função, as habilidades para cozinhar, devendo reconhecer o uso desses utensílios, associando as etapas do cozinhar, nomear (ingredientes), reconhecer seu uso e aspectos. Dessa forma, as AIVDs que compõem o software foram criadas a partir do questionário Pfeffer.

Os próximos exercícios não se encontram diretamente escritos na escala de Pfeffer, mas envolvem o Índice de Katz e as Medida Independência Funcional (MIF). São habilidades requeridas para algumas das tarefas apresentadas, as quais se unem às funções executivas que designam os processos cognitivos de controle e integração destinados à execução de comportamento dirigido aos objetivos. Dessa forma, o idoso deve ser capaz de lembrar-se de seus compromissos, necessitando estar orientado no tempo e espaço como, por exemplo, verificar a hora de tomar medicação. Consequentemente, sendo importante perceber se o relógio encontra-se parado, se o horário está correto e se encontrando capaz de acertar os ponteiros, caso seja necessário.

Quando se avalia o manuseio do dinheiro, presente no jogo quatro, explora-se o processo atencional, a memória de trabalho e o sequenciamento de raciocínio e ações - afinal o idoso necessita realizar cálculos matemáticos para obter a resposta certa, como a soma dos algarismos de uma data ou a resolução de um problema. Nesse jogo, aparece o sequenciamento de notas, com objetivo de realizar cálculo para pagamento de determinado objeto, sendo necessário o recebimento do dinheiro e o troco. Relaciona-se à percepção visual (cores/tamanhos) e à memória de trabalho. Fazendo um paralelo com o exercício das lâmpadas, no qual as mesmas habilidades (atenção, memória de trabalho, sequenciamento, percepção visual e habilidade viso-motora) são recrutadas durante sua realização.

Para muitas atividades necessita-se de organização, categorização e criação da imagem mental (LIRA; RUGENE; MELO, 2011). Características estas presentes na etapa de organização de cômodos e seus respectivos objetos, na qual se trabalha a memória semântica e a percepção visual, classificação de objetos por cômodos e a organização mental.

A relação entre figura e fundo é um componente da percepção visual humana que repercute de forma mais intensa na vida das imagens e que se encontra vinculado ao pensamento abstrato e à atenção seletiva. Consegue-se identificar melhor um objeto, delimitando seus contornos com mais nitidez, quando ele se destaca, por contraste, sobre um fundo que tende à indefinição e à indistinção, este aspecto é explorado no exercício de sombra. Assim sendo, a forma como o idoso percebe a parte e o todo vai depender da estruturação da sua percepção e de sua capacidade de relacionar suas partes. 
O lavar roupa, além de ser uma AIVD, envolve organização e categorização, pois ao colocar as roupas de maneira aleatória pode estragá-las. Normalmente, o idoso no decorrer do seu viver aprende que primeiro separa-se as roupas claras das escuras, pois pode sair tinta e manchar ou desbotar as mais claras. Assim, as roupas de tons pastel claro devem ir para a pilha de roupas claras, enquanto as coloridas devem ser alocadas nas roupas escuras. Outra opção é separar as roupas pelo tecido, porque os tecidos grossos não devem fazer o mesmo ciclo que os mais delicados, o que pode causar danos (rasgos), por isso, necessita-se dessa separação, além de verificar se podem ir ou não à máquina, se soltam tinta, etc. Apesar de não avaliada na escala, essa AIVD possui conceitos anteriormente mencionados, que são necessários a outras que constam no questionário como o de se manter em conversa sobre assuntos de diferentes categorias, tais como trabalho, política, entre outros, sendo necessário categorizar, realizar julgamento, opinar e criticar.

Num jogo de cartas, precisa-se de atenção seletiva, concentração para planejar e organizar a sequência das cartas em ordem crescente, observando seus valores e a alternância das cores, das letras e dos naipes, além de perceber a vez de jogar e obedecer às regras. Faz-se uso da memória, da criatividade e da capacidade de resolução de problemas, pois apresenta uma fileira contendo as cartas viradas com a figura para baixo, o que impede sua visualização.

Para Engelhardt et al. (2005), a lista de benefícios do jogo de cartas inclui a estimulação do cérebro por ter regras, o qual impõe limites que devem ser obedecidos. Além disso, serve como exercício de atenção, linguagem, processamento visual, memória, raciocínio, resolução de problemas e planejamento. Cada partida estimula diversas áreas cerebrais, entre elas a que é responsável pela visão e as temporais e frontais da memória, que regem, respectivamente, o planejamento, os limites de atuação e o convívio entre pessoas.

Segundo esses pesquisadores, utilizar jogos é uma atividade tão rica que vem sendo aplicada em processos de reabilitação cognitiva realizados com idosos por psicólogos e terapeutas ocupacionais. São utilizadas técnicas baseadas em jogos tradicionais ou virtuais, com o uso da informática. Elas funcionam como "potencializadores terapêuticos" para o desenvolvimento de habilidades perdidas ou aprendizado de outras (ENGELHARDT et al., 2005). Dessa maneira, o jogar cartas em algum momento já fez parte da vida dos idosos, facilitando muitas vezes o seu envolvimento nos jogos computadorizados que inicialmente podem surgir como novidade, colocando-os em contato com a realidade virtual da atualidade, constituindo-se uma porta de entrada para a inclusão digital e permitindo aos idosos se relacionarem com outras pessoas por meio da informática. 
A autonomia e independência do idoso podem ser prejudiciais devido ao declínio cognitivo. O terapeuta ocupacional pode ser de extrema importância para a população idosa, visando manter o desempenho competente uma vez que estudos apontam a melhora em AIVD's e ABVD's após o treino cognitivo (MARRA et al., 2007).

Concluiu-se que o desenvolvimento de uma ferramenta para auxiliar a cognição de idosos não é simples, pois necessita de estudo sobre o desenvolvimento cognitivo, a sua relação com seus declínios e capacidades. Assim, esse software é uma proposta que pode possibilitar a adaptação de acordo com a necessidade do cliente. Os recursos de multimídias favorecem a construção de ferramentas, tornando possível adequação às condições físicas e cognitivas do idoso e potencializando o uso de sua capacidade remanescente.

A modelagem do protótipo mostrou a importância de uma equipe multidisciplinar, a partir da troca de informações sobre como dispor as ideias e o que as ferramentas digitais podem ou não realizar de acordo com o que foi pensado. Esse processo foi muito criativo e demonstrou a necessidade de unir a linguagem de profissionais da saúde com a de profissionais da computação que, algumas vezes, não é tão fácil de realizar. Dessa forma, o uso da informática aliado aos recursos de multimídia poderá servir como ferramenta de auxílio para manter o desempenho ocupacional e a participação do idoso no meio social, oportunizando melhoria da qualidade de vida, a manutenção, a prevenção e diminuição dos declínios cognitivos em idosos.

Os exercícios propostos no software poderão precisar de atualização e ajustes, uma vez que o cérebro se adapta, automatizando o que realiza por ser uma forma de ampliar as áreas de desempenho. Por outro lado, a informática propicia uma forma divertida de conservar a capacidade remanescente e otimizar o que está sendo alterado.

O fato de se utilizar os testes como norteadores para o desenvolvimento desse software, na medida em que eles também são usados para medir as intervenções, auxiliou a forma de propor os exercícios. O computador pode ser considerado um recurso terapêutico ocupacional por trabalhar os diversos componentes e por ser adaptável aos clientes, de fácil utilização e possibilita trabalhar todas as áreas cognitivas, atuando como facilitador do desempenho ocupacional e auxiliar no engajamento do idoso na atualidade, proporcionando aprendizado constante de algo novo que enriquece a experiência pessoal.

O uso de softwares e hardwares precisa ser mais explorado para essa população, pois a inclusão digital do idoso pode beneficiá-lo pela ativação 
cognitiva, lazer, conhecimentos culturais, o que ampliará os projetos de vida, diminuindo o isolamento e a depressão. Espera-se criar uma Oficina de Inclusão Digital para Idosos no IFRJ, onde também será aplicado este software, após o mesmo ser patenteado pelo IFRJ e se tornar domínio público. A partir daí, pode-se mensurar o resultado real do uso da ferramenta em determinado grupo de pessoas ou em um único sujeito.

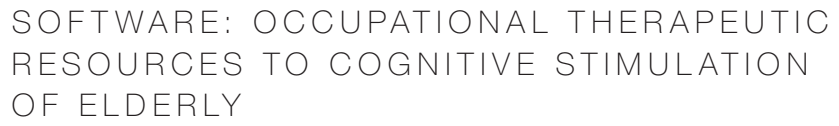

abstract

Elderly with cognitive problems have functional capacity decline, becoming more dependent and with low quality of life. The aim of this study is to develop software based on tests, in everyday activities described in the literature as the most affected in this population and the experience of the project developed at the Federal Institute of Rio de Janeiro. This proposal is justified by studies demonstrate that, through cognitive stimulation, elderly can better carry out their routine activities. Aims at preventing cognitive functioning, improved quality of life and safety in the achievements of everyday activities seeking a more competent performance, greater autonomy and independence. The methodology used was in exploratory character, from the literature review, which showed that Pfeffer's questionnaire, Katz Index, Independence Function Measure linked to the functionality of the activities of daily living and instrumental that forms the basis of the most affected cognitive areas. From these data, the software was divided into ten exercises covering specific areas of cognition, as it may be an occupational therapeutic resource for seniors who need encouragement and assistance in their occupational performance. The information were arranged in relation to the use of color and quantity of elements that facilitate or difficult the access and understanding of the interface. It was concluded that the software is a positive proposal by decreasing energy expenditure, because the achievements of exercises favors independence/dependence, compared the effectiveness and increase the skills required to practice them.

keywords

Aging. Cognitive stimulation. Software. Occupational therapy. 
referências

BADDELEY, Alan; EYSENCK, Hans; ANDERSON, Michael C. Memória. Porto Alegre: Artmed, 2011

BECKERT, Michele; IRIGARAY, Tatiana Quarti; TRENTINI, Clarissa Marceli. Qualidade de vida, cognição e desempenho nas funções executivas de idosos. Estudos de psicologia, Campinas, v. 29, n. 2, p. 155-162, jun. 2012. Disponível em: <http://www. scielo.br/pdf/estpsi/v29n2/a01v29n2.pdf>. Acesso em: 5 nov. 2016.

CAIXETA, Leandro; PINTO, Pedro Henrique. Reserva cerebral, plasticidade e o cérebro do idoso. In: CAIXETA, Leandro; TEIXEIRA, Antônio Lúcio. Neuropsicologia geriátrica: neuropsiquiatria cognitiva em idosos. São Paulo: Artmed, 2014. p. 45-55.

CARLETO, Daniel Gustavo de Sousa et al. Estrutura e prática da terapia ocupacional: domínio e processo. Revista Triângulo, Uberaba, v. 3, n. 2, p. 57-147, jul./dez. 2010. Disponível em: <http://seer.uftm.edu.br/revistaeletronica/index.php/revistatriangulo/ article/view/150/177>. Acesso em: 20 nov. 2016.

CASTRO-CALDAS, Alexandre. O cérebro e as suas funções. In: CASTRO-CALDAS, Alexandre; MENDONÇA, Alexandre (Coord.). A doença de Alzheimer e outras demências em Portugal. Lisboa: Lídel, 2005.

CHAVES, Márcia L. F. et al. Doença de Alzheimer. Avaliação cognitiva, comportamental e funcional. Dementia Neuropsychologia, São Paulo, v. 5, p. 21-23, jun. 2011. Suplemento.

CONSELHO FEDERAL DE FISIOTERAPIA E TERAPIA OCUPACIONAL (COFFITO). Resolução n. 316 de 19 de jul. de 2006. Dispõe sobre a prática de Atividades de Vida Diária, de Atividades Instrumentais da Vida Diária e Tecnologia Assistiva pelo Terapeuta Ocupacional e dá outras providências. Diário Oficial [da] República Federativa do Brasil, Brasilia, DF, 3 ago. 2006. Seção 1, p. 79. Disponível em: <https://www.coffito.gov.br/ nsite/?p=3074>. Acesso em: 5 nov. 2016.

CORRÊA, Antônio Carlos de Oliveira. Memória, aprendizagem e esquecimento: a memória por meio das neurociências cognitivas. São Paulo: Atheneu, 2010.

DIAS, Eliane Golfieri. Associação entre o desempenho de atividades avançadas devida diária e a incidência de declínio cognitivo: estudo SABE. 2014. 146 f. Tese (Doutorado em Ciências)-Faculdade de Saúde Pública, Universidade de São Paulo, São Paulo, 2014.

DRAG, Lauren; BIELIAUSKAS, Linas. Contemporary Review 2009: cognitive aging. Journal of geriatric psychiatry and neurology, Littleton, MA, v. 23, n. 2, p. 75-93, jun. 2010.

ENGELHARDT, Elias et al. Alzheimer's Disease and Proton Magnetic Resonance Spectroscopy of Limbic Regions: a Suggestion of a Clinical-spectroscopic Staging. Arquivos de Neuro-Psiquiatria, São Paulo, v. 63, n. 2a, p. 195-200, June 2005. Disponível em: <http://www.scielo.br/pdf/anp/v63n2a/a01v632a.pdf>. Acesso em: 6 mar. 2017.

FREIRE, Sueli Aparecida; SOMMERHALDER, Cinara. Envelhecer nos tempos modernos. In: NERI, Anita Liberalesso; FREIRE, Sueli Aparecida (Org.). E por falar em boa velhice. Campinas: Papirus, 2000. p. 125-135.

GRIEVE, June; GNANASKARAN, Linda. Cognição: métodos e processos. In:_. Neuropsicologia para terapeutas ocupacionais: cognição no desempenho ocupacional. São Paulo: Santos, 2010. p. 61-80.

LENT, R. Com bilhões de neurônios: conceitos fundamentais da Neurociência São Paulo: Atheneu, 2004.

LIRA, Juliana Onofre de; RUGENE, Olinda Tereza; MELLO, Patrícia Cotting Homem de. Desempenho de idosos em testes específicos: efeito de Grupo de Estimulação. Revista Brasileira de Geriatria e Gerontologia, Rio de Janeiro, v. 14, n. 2, p. 209-220, 
abr./jun. 2011. Disponível em: <http://www.scielo.br/pdf/rbgg/v14n2/v14n2a03.pdf>. Acesso em: 14 out. 2016

LINO, Valéria Teresa Saraiva et al. Adaptação transcultural da Escala de Independência em Atividades da Vida Diária (Escala de Katz). Cadernos de Saúde Pública, Rio de Janeiro, n. 24, p. 103-112, jan. 2008.

LOUREIRO, Ana Paula Leal et al. Reabilitação cognitiva em idosos institucionalizados: um estudo piloto. Revista de Terapia Ocupacional da Universidade de São Paulo, São Paulo, v. 22, n. 2, p. 136-144, maio/ago. 2011. Disponível em: <http://www.revistas. usp.br/rto/article/view/14131/15949>. Acesso em: 9 out. 2016.

MACHADO, Angelo; HAERTEL, Lucia Machado. Neuroanatomia funcional. São Paulo: Atheneu, 2015.

MARRA, T. A. et al. Avaliação das atividades de vida diária de idosos com diferentes níveis de demência. Revista Brasileira de Fisioterapia, São Carlos, v. 11, n. 4, p. 267-273, 2007.

OLIVEIRA, Luciane Paula Batista Araújo de; MENEZES, Rejane Maria Paiva de. Representações de fragilidade para idosos no contexto da estratégia saúde da família. Texto \& Contexto Enfermagem, Florianópolis, v. 20, n. 2, p. 301-309, abr./jun. 2011.

PAPALÉO NETTO, Matheus; CARVALHO FILHO, Eurico Thomaz de. Geriatria: fundamentos, clínica e terapêutica. São Paulo: Atheneu, 2006.

PASCHOAL, Sergio Marcio Pacheco. Autonomia e independência. In: PAPALÉO NETTO, Matheus. Tratado de Gerontologia. São Paulo: Atheneu, 2007. p. 609-620.

PEDROSA, Taís Moraes Campos; TOUTAIN, Lídia Brandão. O Uso das Cores como Informação em Interfaces Digitais. In: CINFORM ENCONTRO NACIONAL DE CIÊNCIA DA INFORMAÇÃO, 4., 2005, Salvador. Anais... Salvador: UFBA, 2005. Disponível em: <http://www.cinform-anteriores.ufba.br/vi_anais/docs/TaisPedrosaLidiaToutain.pdf>. Acesso em: 14 out. 2016.

PFEFFER, R. I. et al. Measurement of Functional Activities in Older Adults in the Community. Journal of Gerontology, v. 37, n. 3, p. 323-329, maio 1982.

PORTO, Fabio Henrique de Gobbi; NITRINI, Ricardo. Neuropsicologia do envelhecimento normal e do comprometimento cognitivo leve. In: CAIXETA, Leandro; TEIXEIRA, Antônio Lúcio. Neuropsicologia Geriátrica: neuropsiquiatria cognitiva em idosos. São Paulo: Artmed, 2014. p. 141-152

RODA, Fabiana Castilho Carvalho. Treino de memória episódica com ênfase em categorização para idosos saudáveis. In: SANTOS, Franklin Santana; SILVA, Thaís Bento Lima da; ALMEIDA, Evany Bettine de. Estimulação cognitiva para idosos: ênfase em memória. Rio de Janeiro: Atheneu, 2013. p. 69-73.

SANTOS, Ariene Angelini dos; PAVARINI, Sofia Cristina lost. Funcionalidade de idosos com alterações cognitivas em diferentes contextos de vulnerabilidade social. Acta Paulista de Enfermagem, São Paulo, v. 24, n. 4, p. 520-526, 2011. Disponível em: <http://www. scielo.br/pdf/ape/v24n4/a12v24n4.pdf>. Acesso em: 5 nov. 2016.

SANTOS, Izabel Borges dos et al. Oficinas de estimulação cognitiva adaptadas para idosos analfabetos com transtorno cognitivo leve. Revista Brasileira de Enfermagem, Brasília, DF, v. 65, n. 6, p. 962-968, dez. 2012. Disponível em: <http://www.scielo.br/ pdf/reben/ v65n6/a12v65n6.pdf>. Acesso em: 9 out. 2016.

STERNBERG, Robert J. Psicologia cognitiva. Porto Alegre: Artmed, 2000.

SILVA, Thaís Bento Lima da et al. Estudos de treino cognitivo realizados no Brasil. In: SANTOS, Franklin Santana et al. (Ed.). Estimulação cognitiva para idosos: ênfase em memória. Rio de Janeiro: Atheneu, 2013. p. 103-112.

STHAL, Hellen Cristina; BERTI, Heloisa Wey; PALHARES, Valéria de Castillho. Grau de dependência de idosos hospitalizados para realização das atividades básicas da vida 
diária. Texto \& Contexto Enfermagem, Florianópolis, v. 20, n. 1, p. 59-67, jan./mar. 2011. Disponível em: <http://www.scielo.br/pdf/tce/v20n1/07.pdf>. Acesso em: 2 jul. 2015.

TALMELLI, Luana Flávia da Silva et al. Nível de independência funcional e déficit cognitivo em idosos com doença de Alzheimer. Revista da Escola de Enfermagem da Universidade de São Paulo, São Paulo, v. 44, n. 4, p. 933-939, 2010. Disponível em: <http://www.scielo.br/pdf/reeusp/v44n4/11.pdf>. Acesso em: 9 out. 2016.

TALMELLI, Luana Flávia da Silva et al. Doença de Alzheimer: declínio funcional e estágio da demência. Acta Paulista de Enfermagem, São Paulo, v. 26, n. 3, p. 219-225, 2013

TAMAI, Silvia Affini Borsoi. Atividade em terapia ocupacional. In: JACOB FILHO, Wilson. Prática a caminho da senecultura. São Paulo: Atheneu, 2003.

WATANABE, Marli Kiyoko Fujikawa; TSUKIMOTO, Denise Rodrigues; TSUKIMOTO Gracinda Rodrigues. Terapia Ocupacional e o uso do computador como recurso terapêutico. Acta Fisiátrica, São Paulo, v. 10, n. 1, p. 17-20, 2003. Disponível em: <http://www.revistas.usp.br/actafisiatrica/article/viewFile/102416/100739>. Acesso em: 20 ago. 2016.

Data de submissão: 11/11/2014

Data de aprovação: 25/03/2017 
